\title{
An exhaustible resources model in a dynamic input-output framework: a possible reconciliation between Ricardo and Hotelling
}

\author{
Biao Huang*
}

${ }^{*}$ Correspondence:

huangbiao@ruc.edu.cn

Renmin University of China,

Beijing, China

\begin{abstract}
This study investigates the problem of exhaustible resources using a dynamic inputoutput model with classical features. Following past research on the topic, further reconciliation can be made between the analyses of Ricardo and Hotelling on exhaustible resources by introducing resource-searching activities. The study's model is based on a given real wage rate and a given consumption vector. The model reveals that the paths of prices, royalties, rents, intensities of production and searching processes can be determined once a sequence of profit rates as well as the initial amounts of commodities and resources are given. This paper also discusses the circumstances under which commodity prices are constant when exhaustible resources exist, based on the model presented.
\end{abstract}

Keywords: Exhaustible resources, Dynamic input-output model, Classical theory, Searching, Capacity constraints on extraction

\section{Introduction}

This study investigates the problem of exhaustible resources using a dynamic inputoutput model with classical features. Although discussions on whether exhaustible resources set a limit to economic growth continue in debate to this day, one must acknowledge that exhaustible resources are and will remain of great importance to most economies. Solow's opinion that the topic of exhaustible (or non-renewable) resources is "important, contemporary, and perennial" (Solow 1974, p. 1) in economics is indeed still very relevant.

The modern theory of exhaustible resources generally stems from the well-known Hotelling rule (Hotelling 1931). According to the Hotelling rule, the prices of exhaustible resources in situ must increase at a rate equal to that of the profit, provided that free competition prevails, due to the fact that the storage of exhaustible resources requires a normal rate of profit as do other production processes. Since resources are generally used in the production of many, if not all commodities, it is appropriate to conduct research on exhaustible resources within a multi-sectoral framework. In 
addition, since the Hotelling rule seems to imply that the prices of many, if not all, commodities are subject to change, a dynamic analysis is appropriate. Based on these two considerations, the dynamic input-output model is the best option for carrying out this study's research.

The existing academic literature on exhaustible resources that utilises input-output methods focuses primarily on the interdependence of exhaustible resources or energy, economic growth, and the environment. Therein, the evolution of the price of exhaustible resources is usually not discussed or simply assumed to be exogenous. For example, much research has been devoted analysing the factors that affect energy consumption using structural decomposition analysis (SDA) via hybrid energy input-output models (e.g. Lin and Polenske 1995; Mukhopadhyaya and Chakraborty 1999; Kagawa and Inamura 2001, 2004; Dietzenbacher and Stage 2006), on the impact of non-renewable resources on economic growth (e.g. Dobos and Floriska 2005), on tracking energy paths (e.g. Treloar 1997), on reducing energy requirements (e.g. Wilting et al. 1999), and on the relationship between energy and the environment (e.g. Weber and Schnabl 1998; Karten and Schleicher 1999). In these models, the prices of exhaustible resources specifically are not typically discussed. Dejuan et al. (2013) consider the impact of the prices of energy on technological coefficients, but in their analyses price evolvements are exogenous. In this article, the economic dynamics of both quantity and price will be put under comprehensive investigation in a dynamic input-output model built with classical features.

It should be noted that the dynamic input-output model used in this study differs slightly from the dynamic Leontief model. One of the most common ways to make a static input-output model dynamic is by introducing "capital" stock and the "stock-flow" matrix, as proposed by Leontief (1953, 1970). However, this dynamic Leontief model has several theoretical problems due to the rigorous assumptions needed for empirical research. Specifically, these theoretical problems include the irreversibility of capital accumulation (Leontief 1953; McManus 1957), the singularity problem, causal indeterminacy (Dorfman et al. 1958; Takayama 1974), as well as problems of stability and dual stability/instability (Sargan 1958; Morishima 1959; Solow 1959; Jorgenson 1960, 1961; Steenge 1990).

Different remedies have been put forward for addressing these problems; for instance, Leontief himself (1953) proposed a "multi-phase" process to deal with the problem of irreversibility. The models' singularity problem can also be solved through many different means (e.g. Kendrik 1972; Livesey 1973; Luenberger and Arbel 1977; Jodar and Merello 2010). Causal indeterminacy can be avoided by allowing for extra production capacity, rather than resorting to full capacity utilisation (Duchin and Szyld 1985), or by changing the Leontief model into a planning model and introducing the non-negativity of output (Solow 1959). For the dual stability/instability problem, one can replace the assumption of perfect foresight with an assumption that firms make investments based on past experience (Aoki 1977). However, some notable imperfections in the dynamic Leontief model remain that must be acknowledged. First of all, the model cannot deal with the problem of joint production. Secondly, even though the static input-output model has a classical tradition (Kurz and Salvadori 2000a, 2006) regardless of illegitimate assumptions (e.g. value-added coefficients in price theory), its treatment of capital 
in the dynamic model is typically neo-classical which cannot survive the critiques raised by Sraffa's work (Sraffa 1960) and the following capital controversies.

A second way to make the static input-output model dynamic is by introducing expenditure lags, as was done by Solow (1952). However, in this kind of dynamic model, the input-output matrix represents the expenditure relations rather than production technology.

Given these considerations, for this study a dynamic input-output model with production lags and classical features is used. This specific model construction has the following three advantages. First, its input-output matrix still represents production technology. Second, it is possible to address joint production using this methodological framework. Third and more importantly, this model, which is Sraffa-von Neumann orientated and which has a classical tradition, does not suffer from the problem of "capital" as does the neo-classical theory. Hence, this study's model is more logically consistent.

\section{Background}

The issue of exhaustible resources in modern classical theory is still in a state of intense debate. Sraffa only mentioned natural resources in passing: 'Natural resources which are used in production, such as land and mineral deposits... (Sraffa 1960 p. 74). Several scholars have subsequently investigated the theory of exhaustible resources using Sraffian or classical frameworks (e.g. Parrinello 1983, 2001, 2004; Bidard and Erreygers 2001a, b; Schefold 1989, 2001; Lager 2001; Ravagnani 2008; as well as Kurz and Salvadori 1995, 1997, 2000b, 2001, 2009, 2011). A survey on the research contributions made by many researchers on the topic was compiled by Kurz and Salvadori (2015). However, there has been no consensus among these models, as exemplified at the proceedings of a symposium presented by Metroeconomica in 2001. To this day, the issue seems to be far from settled.

The research conducted in this study is built on and inspired primarily by the work of Kurz and Salvadori. The preliminary results from initial their studies on exhaustible resources (Kurz and Salvadori 1995, 1997) were later revised and improved using a dynamic input-output model (Kurz and Salvadori 2000b, 2001), which enables the tracking of the time paths of prices, royalties, and other endogenous variables. In their subsequent work, Kurz and Salvadori (2009) offer new interpretations to the treatment of exhaustible resources by Ricardo. They clarify that Ricardo's analysis of exhaustible resources starts from his discussion on the differences between rent and profit in Chapter II of his Principles (Ricardo 1817), and that what we call "royalties" are in actuality comprised in profits in Ricardo's analysis.

Based on their systematic investigation of Ricardo's work, Kurz and Salvadori (2009) point out that although the Hotelling rule is not elaborated upon by Ricardo, it does not necessarily mean that Ricardo's analyses are wrong, incomplete, or insufficient. The fundamental differences between the analyses of Ricardo and those of Hotelling are found in their varied assumptions. From Ricardo's point of view, there are searching activities such that each exhausted mine is replaced by a newly discovered mine with the same quality and quantity, and the searching costs in terms of labour and commodities are constant. In addition, there is capacity constraint on extraction in each mine. Under this theory, royalties are treated as a sub-category of profits, and are not introduced 
explicitly. Rather, the rents of mines caused by different fertilities are a considered wholly different concept. On the other hand, from Hotelling's point of view, the amount of one homogeneous and exhaustible resource is known and given at the outset. The extraction of resource at each time is constrained only by the remaining pool of the resource left over from the preceding point in time.

Both of the arguments developed by Ricardo and Hotelling on exhaustible resources are helpful for improving our understanding on this issue. The ideas put forward by Ricardo and Hotelling can be incorporated into a single framework. This was done by Kurz and Salvadori (2009), who provide a formalisation of exhaustible resources with explicit capacity constraints on extraction, clearly distinguishing three types of property incomes: profits, royalties, and rents. A numerical example was subsequently provided by them (Kurz and Salvadori 2011) to shed more light on this issue.

This study, following the work of Kurz and Salvadori (2009, 2011), seeks to contribute to the reconciliation of Ricardo's and Hotelling's analyses on exhaustible resources by introducing resource-searching activities. More specifically, this study is aims to expand on the following aspects. First, it seeks to introduce searching activities and to provide a sufficient and necessary condition for the existence of solutions to the model. Given a real wage rate and a consumption vector, the model indicates that the paths of prices, royalties, rents, intensities of commodity production, and resource-searching processes can be determined once a sequence of profit rates as well as the initial amounts of commodities and resources are given. Second, it is found that some well-defined circumstances under which commodity prices are constant, as initially discussed by Kurz and Salvadori $(2009,2011)$, can be represented by the study's model as well.

Two points need to be stressed further. First, the method used in this study is similar to that of Solow in his work on the generalisation of the dynamic input-output system (Solow 1959). However, the theory diverges in some notable respects. Due to the difficulties faced by neo-classical capital theory, the model in this study does not assume that distributive variables are determined by the demand for, or the supply of, factors. For this study, one distributive variable (the real wage rate) is assumed to be given exogenously (i.e. its determination lies outside the system), while the remaining distributive variables are determined endogenously. It is because of this that the model used in this study can be said to preserve some classical features.

Second, in order to make the model more manageable, there is an assumption of perfect foresight. That is to say, when prices are bound to change over time, agents are aware of it, and are accurately aware of how prices change. This assumption is very strong. Since the decisions made by firms and individuals are usually based on their expectations for the future, and because all future states cannot be known with certainty, a discussion on the expectation cannot be avoided in principle. However, introducing expectations not only complicates the issues to be investigated in this study, but also makes it difficult, if not impossible, to achieve confident results. This is because any results will depend on the assumptions made on the formation of expectations. A detailed discussion on expectations lies beyond the scope of this study. To resolve this impasse, this study adopts one of the simplest expectations: perfect foresight. As such, this paper's analysis can be considered the preliminary result of a more satisfactory investigation on the subject. 
Table 1 Input-output patterns

\begin{tabular}{|c|c|c|c|c|c|c|}
\hline & \multicolumn{3}{|l|}{ Inputs } & & \multicolumn{2}{|l|}{ Outputs } \\
\hline & Commodities & Resources & Labour & & Commodities & Resources \\
\hline Commodities & A & C & $l_{1}$ & $\rightarrow$ & B & 0 \\
\hline Seaching & $\mathrm{F}$ & 0 & 12 & $\rightarrow$ & 0 & $\mathrm{D}$ \\
\hline Storage & 0 & I & 0 & $\rightarrow$ & 0 & । \\
\hline
\end{tabular}

This paper is organised as follows. Basic definitions and the study's model are provided in Sect. 3. The dynamics of quantity and price are explored in Sect. 4, which gives the conditions for the solutions of the study's model. Section 5 discusses the circumstances under which prices are found to be constant based on the model presented. Notably, the circumstances seem contradictory to the Hotelling rule. Section 6 concludes.

\section{Basic definitions and the study's model}

The formalisation of this study's model is based on the following assumptions. It is assumed that there are $n$ perfectly divisible commodities in the economy, which are produced by $m_{1}\left(m_{1}>n\right)$ constant-returns-to-scale processes. There are $s$ kinds of resources provided by nature, but only part of the total amount is known at the outset. The remaining resource pool is progressively discovered with $m_{2}\left(m_{2}>s\right)$ processes using commodities and labour.

Instead of extracting the resources, the owners can choose to store them. Hence, there are $s$ processes for storage. Each process $i$ producing commodities is represented by a quintuplet $\left(\boldsymbol{a}_{i}, \boldsymbol{c}_{i}, l_{1 i}, \boldsymbol{b}_{i}, \mathbf{0}\right)$, where $\boldsymbol{a}_{i}^{\mathrm{T}}=\left(a_{i 1}, \ldots, a_{i n}\right)$ is the commodity inputs vector, ${ }^{1} \boldsymbol{c}_{i}^{\mathrm{T}}=\left(c_{i 1}, \ldots, c_{i s}\right)$ is the resource inputs vector, $l_{1 i}$ is the labour input scalar, and $\boldsymbol{b}_{i}^{\mathrm{T}}=\left(b_{i 1}, \ldots, b_{i n}\right)$ is the commodity outputs vector. Each process $j$ searching resources is represented by $\left(\boldsymbol{f}_{j}, \mathbf{0}, l_{2 j}, \mathbf{0}, \boldsymbol{d}_{j}\right)$, where $\boldsymbol{f}_{j}^{\mathrm{T}}=\left(f_{j 1}, \ldots, f_{j n}\right)$ is the commodity inputs vector, $l_{2 j}$ is the labour input scalar, and $\boldsymbol{d}_{j}^{\mathrm{T}}=\left(d_{j 1}, \ldots, d_{j s}\right)$ is the resource outputs vector. The whole technology at time $t$ is represented by the following matrices:

$$
\begin{aligned}
\mathbf{A} & =\left[\boldsymbol{a}_{1}, \boldsymbol{a}_{2}, \ldots, \boldsymbol{a}_{m_{1}}\right]^{\mathrm{T}} \\
\mathbf{C} & =\left[\boldsymbol{c}_{1}, \boldsymbol{c}_{2}, \ldots, \boldsymbol{c}_{m_{1}}\right]^{\mathrm{T}} \\
\boldsymbol{l}_{1} & =\left[l_{11}, l_{12}, \ldots, l_{1 m_{1}}\right]^{\mathrm{T}} \\
\mathbf{B} & =\left[\boldsymbol{b}_{1}, \boldsymbol{b}_{2}, \ldots, \boldsymbol{b}_{m_{1}}\right]^{\mathrm{T}} \\
\mathbf{F} & =\left[\boldsymbol{f}_{1}, \boldsymbol{f}_{2}, \ldots, \boldsymbol{f}_{m_{2}}\right]^{\mathrm{T}} \\
\boldsymbol{l}_{2} & =\left[l_{21}, l_{22}, \ldots, l_{2 m_{2}}\right]^{\mathrm{T}} \\
\mathbf{D} & =\left[\boldsymbol{d}_{1}, \boldsymbol{d}_{2}, \ldots, \boldsymbol{d}_{m_{2}}\right]^{\mathrm{T}}
\end{aligned}
$$

The processes are ordered so that the first $m_{1}$ processes produce commodities, the $m_{2}$ processes thereafter search for resources, and the remaining $s$ processes store resources. All processes are listed in Table 1.

Technology producing commodities is assumed to be time invariant, meaning $\mathbf{A}, \mathbf{C}$, $\boldsymbol{l}_{1}$ and $\mathbf{B}$ are constant. However, technology of searching resources is not necessarily

\footnotetext{
${ }^{1}$ For this paper, the transposition of a vector or matrix is denoted by the superscript $T$.
} 
time invariant. The costs for searching for one unit of a certain resource may increase as a result of the increased difficulties in locating any remaining resources. The costs for searching for one unit of a certain resource may also decrease due to increased experience or technological progress as relevant to searching for resources.

For this study, and in order to simplify analysis, it is assumed that searching costs are non-decreasing. In order to compare the searching costs among different periods, (F, $\left.\boldsymbol{l}_{2}\right)$ are assumed to be time invariant, while non-decreasing searching costs are manifest in the changes in $\mathbf{D}$ over time. In addition, note that the joint searching of resources is not assumed (i.e. there is only one positive component in $\boldsymbol{d}_{j}$, and the others are zero). Formally, this can be stated as follows.

Assumption 1 For each $t \in \mathbb{N},\left(\mathbf{F}, \boldsymbol{l}_{2}, \mathbf{0}, \mathbf{D}\right)_{t}$ is known and given, and the following relationships hold.

$$
\begin{aligned}
\left(\mathbf{F}, \boldsymbol{l}_{2}\right)_{t} & =\left(\mathbf{F}, \boldsymbol{l}_{2}\right)_{t+1} \\
\mathbf{D}_{t+1} & =\alpha \mathbf{D}_{t}
\end{aligned}
$$

where $\mathbb{N}$ denotes the set of all natural numbers, and $\alpha \in(0,1]$ is a real number.

In the assumption presented above, if $\alpha=1$, the searching costs (in terms of commodities and labour) are constant. Otherwise, the searching costs are increasing.

Three different types of property income are distinguished: royalties, rents, and profits. Specifically, royalties are the profits that the owners of exhaustible resources will earn in order to keep their capital 'crystallised' in their respective resource mines. Rents are the income earned by these owners generated by the differences in fertilities of resource mines. Profits are the income earned by capitalists for using their capital. These distinctions are important because the laws that regulate these types of incomes are different.

More formally, $\boldsymbol{p}_{t}, \boldsymbol{y}_{t}, \boldsymbol{q}_{t}\left(t \in N_{0}\right.$, the set of all non-negative integers) denotes the prices of commodities, royalties and rents paid to the owners of the resources. Let $r_{t}$ denote the nominal rate of profit at time $t$, and $\boldsymbol{w}_{t}$ a bundle of wage goods which is assumed to be exogenously given and constant.

Moving on to quantity side of the model, $x_{t}$ and $s_{t}(t \in \mathbb{N})$ represent the intensities of processes that produce commodities and the processes for searching for resources, respectively. Let $z_{t}\left(t \in \mathbb{N}_{0}\right)$ serve as the amount of exhaustible resources known at time $t$. It is assumed that workers consume all their incomes (a typical classical assumption) and that the annual consumption by non-workers is proportional to $\delta$, a bundle of commodities, which is given and constant. More specifically, the non-workers' consumption is assumed to be $\gamma$ units of consumption vector $\delta$, where $\gamma$ is endogenously determined. Let a vector $\boldsymbol{h}$ serve as the capacity constraints on extraction, whose elements represent the maximum amount of resources that can be extracted at any given time. ${ }^{2}$ Finally, the initial amounts of resources and commodities are known and given as $\bar{z}$ and $\boldsymbol{v}$, respectively. ${ }^{3}$

\footnotetext{
${ }^{2}$ It is possible that the capacity constraints on extraction are time-variant due to breakthroughs in technological progress or increased infrastructure investments. To simplify analysis, it is assumed in this study that the capacity constraints on extraction are given and constant. However, this serves as a good example for illustrating how rents can arise on the resource mines.

${ }^{3}$ It is possible that searching activities are related to amount of resources and/or to capacity constraints. However, in formalising these relationships, this consideration will not only greatly complicate the issue, but will also make the model unmanageable, if not impossible to resolve. As a preliminary research investigation, these possible relationships are rather put aside for future consideration.
} 
Based on the assumptions noted above, and in the condition of free competition, the following inequalities and equations hold.

$$
\begin{aligned}
& \mathbf{B} \boldsymbol{p}_{t+1} \leqq\left(\mathbf{A} \boldsymbol{p}_{t}+\mathbf{C} \boldsymbol{y}_{t}+\mathbf{C} \boldsymbol{q}_{t}\right)\left(1+r_{t}\right)+\boldsymbol{l}_{1} \boldsymbol{w}^{\mathrm{T}} \boldsymbol{p}_{t+1} \\
& \boldsymbol{x}_{t+1}^{\mathrm{T}} \mathbf{B} \boldsymbol{p}_{t+1}=\boldsymbol{x}_{t+1}^{\mathrm{T}}\left[\left(\mathbf{A} \boldsymbol{p}_{t}+\mathbf{C} \boldsymbol{y}_{t}+\mathbf{C} \boldsymbol{q}_{t}\right)\left(1+r_{t}\right)+\boldsymbol{l}_{1} \boldsymbol{w}^{\mathrm{T}} \boldsymbol{p}_{t+1}\right] \\
& \boldsymbol{y}_{t+1} \leqq\left(1+r_{t}\right) \boldsymbol{y}_{t} \\
& \boldsymbol{z}_{t+1}^{\mathrm{T}} \boldsymbol{y}_{t+1}=\left(1+r_{t}\right) \boldsymbol{z}_{t+1}^{\mathrm{T}} \boldsymbol{y}_{t} \\
& \mathbf{D}_{t+1} \boldsymbol{y}_{t+1} \leqq \mathbf{F} \boldsymbol{p}_{t}\left(1+r_{t}\right)+\boldsymbol{l}_{2} \boldsymbol{w}^{\mathrm{T}} \boldsymbol{p}_{t+1} \\
& \boldsymbol{s}_{t+1}^{\mathrm{T}} \mathbf{D}_{t+1} \boldsymbol{y}_{t+1}=\boldsymbol{s}_{t+1}^{\mathrm{T}}\left[\mathbf{F} \boldsymbol{p}_{t}\left(1+r_{t}\right)+\boldsymbol{l}_{2} \boldsymbol{w}^{\mathrm{T}} \boldsymbol{p}_{t+1}\right] \\
& \boldsymbol{v}^{\mathrm{T}} \geqq \boldsymbol{x}_{1}^{\mathrm{T}} \mathbf{A}+\gamma \boldsymbol{\delta}^{\mathrm{T}}+\boldsymbol{s}_{1}^{\mathrm{T}} \mathbf{F} \\
& \boldsymbol{v}^{\mathrm{T}} \boldsymbol{p}_{0}=\left(\boldsymbol{x}_{1}^{\mathrm{T}} \mathbf{A}+\gamma \boldsymbol{\delta}^{\mathrm{T}}+\boldsymbol{s}_{1}^{\mathrm{T}} \mathbf{F}\right) \boldsymbol{p}_{0} \\
& \boldsymbol{x}_{t+1}^{\mathrm{T}}\left(\mathbf{B}-\boldsymbol{l}_{1} \boldsymbol{w}^{\mathrm{T}}\right)-\boldsymbol{s}_{t+1}^{\mathrm{T}} \boldsymbol{l}_{2} \boldsymbol{w}^{\mathrm{T}} \geqq \boldsymbol{x}_{t+2}^{\mathrm{T}} \mathbf{A}+\gamma \boldsymbol{\delta}^{\mathrm{T}}+\boldsymbol{s}_{t+2}^{\mathrm{T}} \mathbf{F} \\
& {\left[\boldsymbol{x}_{t+1}^{\mathrm{T}}\left(\mathbf{B}-\boldsymbol{l}_{1} \boldsymbol{w}^{\mathrm{T}}\right)-\boldsymbol{s}_{t+1}^{\mathrm{T}} \boldsymbol{l}_{2} \boldsymbol{w}^{\mathrm{T}}\right] \boldsymbol{p}_{t+1}=\left(\boldsymbol{x}_{t+2}^{\mathrm{T}} \mathbf{A}+\gamma \boldsymbol{\delta}^{\mathrm{T}}+\boldsymbol{s}_{t+2}^{\mathrm{T}} \mathbf{F}\right) \boldsymbol{p}_{t+1}} \\
& \boldsymbol{z}_{0}^{\mathrm{T}} \geqq \boldsymbol{x}_{1}^{\mathrm{T}} \mathbf{C}+\boldsymbol{z}_{1}^{\mathrm{T}} \\
& \boldsymbol{z}_{0}^{\mathrm{T}} \boldsymbol{y}_{0}=\left(\boldsymbol{x}_{1}^{\mathrm{T}} \mathbf{C}+\boldsymbol{z}_{1}^{\mathrm{T}}\right) \boldsymbol{y}_{0} \\
& \boldsymbol{z}_{t}^{\mathrm{T}}+\boldsymbol{s}_{t}^{\mathrm{T}} \mathbf{D}_{t} \geqq \boldsymbol{x}_{t+1}^{\mathrm{T}} \mathbf{C}+\boldsymbol{z}_{t+1}^{\mathrm{T}} \\
& \left(z_{t}^{\mathrm{T}}+\boldsymbol{s}_{t}^{\mathrm{T}} \mathbf{D}_{t}\right) \boldsymbol{y}_{t}=\left(\boldsymbol{x}_{t+1}^{\mathrm{T}} \mathbf{C}+\boldsymbol{z}_{t+1}^{\mathrm{T}}\right) \boldsymbol{y}_{t} \\
& \boldsymbol{x}_{t+1}^{\mathrm{T}} \mathbf{C} \leqq \boldsymbol{h}^{\mathrm{T}} \\
& \boldsymbol{x}_{t+1}^{\mathrm{T}} \boldsymbol{C} \boldsymbol{q}_{t}=\boldsymbol{h}^{\mathrm{T}} \boldsymbol{q}_{t} \\
& z_{0}=\bar{z} \\
& \sum_{t=0}^{\infty} \frac{\boldsymbol{\delta}^{\mathrm{T}} \boldsymbol{p}_{t}}{\prod_{\tau=0}^{t-1}\left(1+r_{t}\right)}=1
\end{aligned}
$$




$$
\gamma>0, \quad \boldsymbol{p}_{t} \geqq \mathbf{0}, \quad \boldsymbol{y}_{t} \geqq \mathbf{0}, \quad \boldsymbol{q}_{t} \geqq \mathbf{0}, \quad \boldsymbol{z}_{t} \geqq \mathbf{0}, \quad \boldsymbol{x}_{t} \geqq \mathbf{0}, \quad \boldsymbol{s}_{t} \geqq \mathbf{0}
$$

Inequality (1a) means that no individual can obtain extra profits by producing commodities at time $t$. Equation (1b) means that if there is a process incurring extra costs, then the process is not operated at time $t+1$. Inequality (1c) presents how no extra profits can be obtained from the storing of resources from $t$ to $t+1$. Equation (1d) means that if the storing activity of one resource cannot obtain the nominal rate of profit at time $t$, then the resource is no longer available at time $t+1$. Inequality $(1 \mathrm{e})$ means that no extra profits can be obtained by discovering resources at time $t$. Equation (1f) shows that if one searching process incurs extra costs, then this process is not operated at time $t+1$. Inequalities $(1 \mathrm{~g})$ and (1i) mean that the amount of commodities at time $t$ cannot be smaller than the amount of commodities required for production and consumption at time $t+1$. Equations (1h) and (1j) mean that if an amount of one commodity at time $t$ is larger than needed, then the corresponding price of this commodity is zero. Inequalities $(1 \mathrm{k})$ and $(1 \mathrm{~m})$ show that the amount of resources known at time $t$, plus the resources discovered at time $t$, cannot be less than the amount of resources known and the resources utilised to produce commodities at time $t+1$. Equations (1l) and (1n) illustrate that if the amount of one kind of resource is strictly larger in the preceding period of time, the royalty of this resource is zero. Inequality (1o) presents how the amount of extracted resources cannot be larger than $\boldsymbol{h}^{4}{ }^{4}$ Equation (1p) shows that if the amount of extraction for one resource $i$ is less than $h_{i}$ (the $i$ th element of $\boldsymbol{h}$ ), then no rent is paid to the owner of the resource. Equation (1q) states that the initial resources are given as $\bar{z}$. Equation (1r) serves as the numéraire equation. The meaning of inequality (1s) is obvious.

Since it is impossible to determine the dynamics of the nominal rates of profits in this model, the sequence of the nominal rates of profits $\left\{r_{t}\right\}$ is assumed to be given. This sequence being given means that the determination of dynamics in $r_{t}$ is externalised from the model. However, the given sequence $\left\{r_{t}\right\}$ does not influence relative actualised prices. This is because if the sequences $\left\{\boldsymbol{p}_{t}\right\},\left\{\boldsymbol{y}_{t}\right\},\left\{\boldsymbol{q}_{t}\right\},\left\{\boldsymbol{z}_{t}\right\},\left\{\boldsymbol{x}_{t+1}\right\},\left\{\boldsymbol{s}_{t+1}\right\}$ serve as a solution to System (1) for the given sequence $\left\{r_{t}\right\}$, then the sequences $\left\{\boldsymbol{p}_{t}^{\prime}\right\},\left\{\boldsymbol{y}_{t}^{\prime}\right\},\left\{\boldsymbol{q}_{t}^{\prime}\right\},\left\{\boldsymbol{z}_{t}\right\}$, $\left\{\boldsymbol{x}_{t+1}\right\},\left\{\boldsymbol{s}_{t+1}\right\}$ serve as a solution to the same system for another given sequence $\left\{\rho_{t}\right\}$, provided the following.

\footnotetext{
${ }^{4}$ The formalisation of capacity constraints on extraction in this model is slightly different from the model found in the work of Kurz and Salvadori $(2009,2011)$. In their model, the capacity constraints on extraction are represented by the following inequalities.

$$
\begin{aligned}
& \boldsymbol{z}_{t}^{\top}+\boldsymbol{s}_{t}^{\top} \mathbf{D}_{t} \leqq \boldsymbol{z}_{t+1}^{\top}+\boldsymbol{h}^{\top} \\
& \left(\boldsymbol{z}_{t}^{\top}+\boldsymbol{s}_{t}^{\top} \mathbf{D}_{t}\right) \boldsymbol{q}_{t}=\left(\boldsymbol{z}_{t+1}^{\top}+\boldsymbol{h}^{\top}\right) \boldsymbol{q}_{t}
\end{aligned}
$$

Note that these two formalisations are not equivalent. Inequality (1o) is implied by inequalities (1m) and inequality $\left({ }^{*}\right)$. Inequality $(1 \mathrm{~m})$ does not consider the situation that there may exist a waste of resources (i.e. that the resources are extracted but not actually used in production). In this vein, the formalisation of capacity constraints on extraction found in the work of Kurz and Salvadori $(2009,2011)$ is more accurate. However, please know that the formalisation in this paper is simplified for ease of analysis.
} 


$$
\begin{aligned}
\boldsymbol{p}_{t}^{\prime} & =\prod_{\tau=0}^{t-1} \frac{1+\rho_{t}}{1+r_{t}} \boldsymbol{p}_{t} \\
\boldsymbol{y}_{t}^{\prime} & =\prod_{\tau=0}^{t-1} \frac{1+\rho_{t}}{1+r_{t}} \boldsymbol{y}_{t} \\
\boldsymbol{q}_{t}^{\prime} & =\prod_{\tau=0}^{t-1} \frac{1+\rho_{t}}{1+r_{t}} \boldsymbol{q}_{t}
\end{aligned}
$$

Based on the reasoning presented above, the sequence $\left\{r_{t}\right\}$ is assumed to be constant and $r_{t}=0$ for the sake of simplifying the expression. Therefore, System (1) can be simplified as follows.

$$
\begin{aligned}
& \left(\mathbf{B}-\boldsymbol{l}_{1} \boldsymbol{w}^{\mathrm{T}}\right) \boldsymbol{p}_{t+1} \leqq \mathbf{A} \boldsymbol{p}_{t}+\mathbf{C} \boldsymbol{y}_{t}+\mathbf{C} \boldsymbol{q}_{t} \\
& \boldsymbol{x}_{t+1}^{\mathrm{T}}\left(\mathbf{B}-\boldsymbol{l}_{1} \boldsymbol{w}^{\mathrm{T}}\right) \boldsymbol{p}_{t+1}=\boldsymbol{x}_{t+1}^{\mathrm{T}}\left(\mathbf{A} \boldsymbol{p}_{t}+\mathbf{C} \boldsymbol{y}_{t}+\mathbf{C} \boldsymbol{q}_{t}\right) \\
& \boldsymbol{y}_{t+1} \leqq \boldsymbol{y}_{t} \\
& \boldsymbol{z}_{t+1}^{\mathrm{T}} \boldsymbol{y}_{t+1}=\boldsymbol{z}_{t+1}^{\mathrm{T}} \boldsymbol{y}_{t} \\
& \mathbf{D}_{t+1} \boldsymbol{y}_{t+1} \leqq \mathbf{F} \boldsymbol{p}_{t}+\boldsymbol{l}_{2} \boldsymbol{w}^{\mathrm{T}} \boldsymbol{p}_{t+1} \\
& \boldsymbol{s}_{t+1}^{\mathrm{T}} \mathbf{D}_{t+1} \boldsymbol{y}_{t+1}=\boldsymbol{s}_{t+1}^{\mathrm{T}}\left(\mathbf{F} \boldsymbol{p}_{t}+\boldsymbol{l}_{2} \boldsymbol{w}^{\mathrm{T}} \boldsymbol{p}_{t+1}\right) \\
& \boldsymbol{v}^{\mathrm{T}} \geqq \boldsymbol{x}_{1}^{\mathrm{T}} \mathbf{A}+\gamma \boldsymbol{\delta}^{\mathrm{T}}+\boldsymbol{s}_{1}^{\mathrm{T}} \mathbf{F} \\
& \boldsymbol{v}^{\mathrm{T}} \boldsymbol{p}_{0}=\left(\boldsymbol{x}_{1}^{\mathrm{T}} \mathbf{A}+\gamma \boldsymbol{\delta}^{\mathrm{T}}+\boldsymbol{s}_{1}^{\mathrm{T}} \mathbf{F}\right) \boldsymbol{p}_{0} \\
& \boldsymbol{x}_{t+1}^{\mathrm{T}}\left(\mathbf{B}-\boldsymbol{l}_{1} \boldsymbol{w}^{\mathrm{T}}\right)-\boldsymbol{s}_{t+1}^{\mathrm{T}} \boldsymbol{l}_{2} \boldsymbol{w}^{\mathrm{T}} \geqq \boldsymbol{x}_{t+2}^{\mathrm{T}} \mathbf{A}+\gamma \boldsymbol{\delta}^{\mathrm{T}}+\boldsymbol{s}_{t+2}^{\mathrm{T}} \mathbf{F} \\
& {\left[\boldsymbol{x}_{t+1}^{\mathrm{T}}\left(\mathbf{B}-\boldsymbol{l}_{1} \boldsymbol{w}^{\mathrm{T}}\right)-\boldsymbol{s}_{t+1}^{\mathrm{T}} \boldsymbol{l}_{2} \boldsymbol{w}^{\mathrm{T}}\right] \boldsymbol{p}_{t+1}=\left(\boldsymbol{x}_{t+2}^{\mathrm{T}} \mathbf{A}+\gamma \boldsymbol{\delta}^{\mathrm{T}}+\boldsymbol{s}_{t+2}^{\mathrm{T}} \mathbf{F}\right) \boldsymbol{p}_{t+1}} \\
& \boldsymbol{z}_{0}^{\mathrm{T}} \geqq \boldsymbol{x}_{1}^{\mathrm{T}} \mathbf{C}+\boldsymbol{z}_{1}^{\mathrm{T}} \\
& \boldsymbol{z}_{0}^{\mathrm{T}} \boldsymbol{y}_{0}=\left(\boldsymbol{x}_{1}^{\mathrm{T}} \mathbf{C}+\boldsymbol{z}_{1}^{\mathrm{T}}\right) \boldsymbol{y}_{0} \\
& \boldsymbol{z}_{t}^{\mathrm{T}}+\boldsymbol{s}_{t}^{\mathrm{T}} \mathbf{D}_{t} \geqq \boldsymbol{x}_{t+1}^{\mathrm{T}} \mathbf{C}+\boldsymbol{z}_{t+1}^{\mathrm{T}}
\end{aligned}
$$




$$
\begin{aligned}
& \left(z_{t}^{\mathrm{T}}+\boldsymbol{s}_{t}^{\mathrm{T}} \mathbf{D}_{t}\right) \boldsymbol{y}_{t}=\left(\boldsymbol{x}_{t+1}^{\mathrm{T}} \mathbf{C}+\boldsymbol{z}_{t+1}^{\mathrm{T}}\right) \boldsymbol{y}_{t} \\
& \boldsymbol{x}_{t+1}^{\mathrm{T}} \mathbf{C} \leqq \boldsymbol{h}^{\mathrm{T}} \\
& \boldsymbol{x}_{t+1}^{\mathrm{T}} \mathbf{C} \boldsymbol{q}_{t}=\boldsymbol{h}^{\mathrm{T}} \boldsymbol{q}_{t} \\
& \boldsymbol{z}_{0}=\overline{\boldsymbol{z}} \\
& \sum_{t=0}^{\infty} \boldsymbol{\delta}^{\mathrm{T}} \boldsymbol{p}_{t}=1
\end{aligned}
$$

$$
\gamma>0, \quad \boldsymbol{p}_{t} \geqq \mathbf{0}, \quad \boldsymbol{y}_{t} \geqq \mathbf{0}, \quad \boldsymbol{q}_{t} \geqq \mathbf{0}, \quad \boldsymbol{z}_{t} \geqq \mathbf{0}, \quad \boldsymbol{x}_{t} \geqq \mathbf{0}, \quad \boldsymbol{s}_{t} \geqq \mathbf{0}
$$

In order to avoid "the end of the world" scenario, it is assumed that the consumption $\delta$ required annually can be produced using a backstop technology (which only uses nonexhaustible resources). Formally, a backstop technology, as denoted by $\left(\overline{\mathbf{A}}, \mathbf{0}, \overline{l_{1}}, \overline{\mathbf{B}}\right)$, is defined by the processes which are obtained from $\left(\mathbf{A}, \mathbf{C}, \boldsymbol{l}_{1}, \mathbf{B}\right)$ by deleting all the processes using exhaustible resources directly, (i.e. a process $\left(\boldsymbol{e}_{i}^{\mathrm{T}} \mathbf{A}, \boldsymbol{e}_{i}^{\mathrm{T}} \mathbf{C}, \boldsymbol{e}_{i}^{\mathrm{T}} \boldsymbol{l}_{1}, \boldsymbol{e}_{i}^{\mathrm{T}} \mathbf{B}\right)$ is in $\left(\overline{\mathbf{A}}, \mathbf{0}, \overline{l_{1}}, \overline{\mathbf{B}}\right)$ if and only if $\boldsymbol{e}_{i}^{\mathrm{T}} \mathbf{C}=\mathbf{0}$, where $\boldsymbol{e}_{i}$ is the $i$ th unite vector). The remaining processes are denoted by $\left(\tilde{\mathbf{A}}, \tilde{\mathbf{C}}, \tilde{\boldsymbol{l}_{1}}, \tilde{\mathbf{B}}\right)$. The existence of a backstop technology is summarised as follows.

Assumption 2 There exists a scalar $r^{*}$ and there are vectors $\boldsymbol{x}^{*}$ and $\boldsymbol{p}^{*}$ which solve the following system.

$$
\begin{aligned}
& \boldsymbol{x}^{\mathrm{T}}\left(\overline{\mathbf{B}}-\overline{\mathbf{A}}-\overline{\boldsymbol{l}}_{1} \boldsymbol{w}^{\mathrm{T}}\right) \geqq \boldsymbol{\delta}^{\mathrm{T}} \\
& \boldsymbol{x}^{\mathrm{T}}\left(\overline{\mathbf{B}}-\overline{\mathbf{A}}-\overline{\boldsymbol{l}}_{1} \boldsymbol{w}^{\mathrm{T}}\right) \boldsymbol{p}=\boldsymbol{\delta}^{\mathrm{T}} \boldsymbol{p} \\
& \overline{\mathbf{B}} \boldsymbol{p} \leqq\left[(1+r) \overline{\mathbf{A}}+\overline{\boldsymbol{l}}_{1} \boldsymbol{w}^{\mathrm{T}}\right] \boldsymbol{p} \\
& \boldsymbol{x}^{\mathrm{T}} \overline{\mathbf{B}} \boldsymbol{p}=x^{\mathrm{T}}\left[(1+r) \overline{\mathbf{A}}+\overline{\boldsymbol{l}}_{1} \boldsymbol{w}^{\mathrm{T}}\right] \boldsymbol{p} \\
& \boldsymbol{x} \geqq \mathbf{0}, \quad \boldsymbol{p} \geqq \mathbf{0}, \quad \boldsymbol{\delta}^{\mathrm{T}} \boldsymbol{p}=1
\end{aligned}
$$

Such processes operated at intensity $\overline{\boldsymbol{x}}$, which is obtained from $\boldsymbol{x}^{*}$ by augmenting it with zeros, will be referred to as 'cost-minimising backstop processes' and are denoted by $\left(\hat{\mathbf{A}}, \mathbf{0}, \hat{\boldsymbol{l}}_{1}, \hat{\mathbf{B}}\right)$. The backstop technology and cost-minimising backstop processes are assumed to have the following characteristics. 
Assumption 3 The processes in the backstop technology converge to the processes $\left(\hat{\mathbf{A}}, \mathbf{0}, \hat{\boldsymbol{l}}_{1}, \hat{\mathbf{B}}\right)$. In other words, for each solution of the following system, there exists a natural number $\theta^{*}$ such that for each $t \geq \theta^{*}$, only the processes $\left(\hat{\mathbf{A}}, \mathbf{0}, \hat{\boldsymbol{l}}_{1}, \hat{\mathbf{B}}\right)$ are operated.

$$
\begin{aligned}
& \left(\overline{\mathbf{B}}-\overline{\boldsymbol{l}}_{1} \boldsymbol{w}^{\mathrm{T}}\right) \boldsymbol{p}_{t+1} \leqq \overline{\mathbf{A}} \boldsymbol{p}_{t} \\
& \boldsymbol{x}_{t+1}^{\mathrm{T}}\left(\overline{\mathbf{B}}-\overline{\boldsymbol{l}}_{1} \boldsymbol{w}^{\mathrm{T}}\right) \boldsymbol{p}_{t+1}=\boldsymbol{x}_{t+1}^{\mathrm{T}} \overline{\mathbf{A}} \boldsymbol{p}_{t} \\
& \boldsymbol{v}^{\mathrm{T}} \geqq \boldsymbol{x}_{1}^{\mathrm{T}} \overline{\mathbf{A}}+\gamma \boldsymbol{\delta}^{\mathrm{T}} \\
& \boldsymbol{v}^{\mathrm{T}} \boldsymbol{p}_{0}=\left(\boldsymbol{x}_{1}^{\mathrm{T}} \overline{\mathbf{A}}+\gamma \boldsymbol{\delta}^{\mathrm{T}}\right) \boldsymbol{p}_{0} \\
& \boldsymbol{x}_{t+1}^{\mathrm{T}}\left(\overline{\mathbf{B}}-\overline{\boldsymbol{l}}_{1} \boldsymbol{w}^{\mathrm{T}}\right) \geqq \boldsymbol{x}_{t+2}^{\mathrm{T}} \overline{\mathbf{A}}+\gamma \boldsymbol{\delta}^{\mathrm{T}} \\
& \boldsymbol{x}_{t+1}^{\mathrm{T}}\left(\overline{\mathbf{B}}-\overline{\boldsymbol{l}}_{1} \boldsymbol{w}^{\mathrm{T}}\right) \boldsymbol{p}_{t+1}=\left(\boldsymbol{x}_{t+2}^{\mathrm{T}} \overline{\mathbf{A}}+\gamma \boldsymbol{\delta}^{\mathrm{T}}\right) \boldsymbol{p}_{t+1} \\
& \sum_{t=0}^{\infty} \boldsymbol{\delta}^{\mathrm{T}} \boldsymbol{p}_{t}=1 \\
& \gamma>0, \quad \boldsymbol{p}_{t} \geqq \mathbf{0}, \quad \boldsymbol{x}_{t+1} \geqq \mathbf{0}
\end{aligned}
$$

Assumption 4 The number of cost-minimising backstop processes is exactly $n$; the matrix $\left[\hat{\mathbf{B}}-\hat{\boldsymbol{l}}_{1} \boldsymbol{w}^{\mathrm{T}}\right]$ is invertible; the matrix $\left[\hat{\mathbf{B}}-\hat{\boldsymbol{l}}_{1} \boldsymbol{w}^{\mathrm{T}}\right]^{-1} \hat{\mathbf{A}}$ is non-negative, and the eigenvalue of the maximum modulus of the matrix $\left[\hat{\mathbf{B}}-\hat{\boldsymbol{l}}_{1} \boldsymbol{w}^{\mathrm{T}}\right]^{-1} \hat{\mathbf{A}}$ is smaller than unity.

Assumption 3 is presented in order to separate the problem of convergence (or gravity) from the study's analysis. The theory that market prices continue to gravitate to the natural prices as determined by cost-minimising technique is well elaborated upon by classical economists, and it is also advocated by some early neo-classical economists, such as Marshall, Walras, and Wicksell. Even though there are debates on how to formally explain the convergence problem in modern classical theory (e.g. see a survey by Bellino 2011), it is still legitimate to use it as a reasonable assumption, given the fact that plenty of empirical observations support the idea of convergence (Petri 2011). In this study, Assumption 4 is made in order to simplify analysis from the complexities 
presented when considering pure joint production, ${ }^{5}$ and it certainly holds if only single production prevails.

After establishing the model's basic framework in the context of this study, an explanation is offered into how Ricardo and Hotelling's ideas on exhaustible resources are represented in the model itself. As explained earlier, Ricardo and Hotelling's analyses on exhaustible resources are based upon different assumptions.

To elaborate further, and in the context of this study's model, we start with Ricardo's perspective.

(R1) After each mine is exhausted, another mine with the same characteristics can be found. In other words, there exist sequences $\left\{\boldsymbol{x}_{t}\right\}$ and $\left\{\boldsymbol{s}_{t}\right\}$, such that the following inequality holds.

$$
\boldsymbol{s}_{t}^{\mathrm{T}} \mathbf{D} \geqq \boldsymbol{x}_{t+1}^{\mathrm{T}} \mathbf{C} .
$$

(R2) Searching costs are constant. That is $\alpha=1$, or $D_{t}=D_{t+1}$ for $t>0$.

(R3) There exists a capacity constraint on extraction in each mine, which is represented here by the corresponding element of $\boldsymbol{h}$.

In Hotelling's world:

(H1) There exists only one kind of resource, with a quantity that is given and known. That is to say $s=1$ and $\bar{z}$ is given and known.

(H2) There exist no capacity constraints on extraction: $\boldsymbol{h}$ is close to infinity.

(H3) There are no searching activities. For instance, $D_{t}=0$ for all $t>0$.

Hence, the Hotelling rule does not hold in all circumstances. On the other hand, Ricardo's analyses on exhaustible resources are found to be neither incomplete nor inferior. It can be seen that both Ricardo and Hotelling's ideas on exhaustible resources are incorporated into this study's model. The implications behind the Hotelling rule as well as Ricardo's analyses will be analysed more comprehensively in Sect. 5. Nevertheless, we must first investigate the model's dynamics of quantity and price.

\section{Methods and analyses}

\subsection{The economic dynamics of quantity and price}

Let us first simplify the analysis and assume that the total amounts of resources are given, and that the searching costs for those resources are negatively related to the amount of unknown resources. Since the remaining resources will be diminishing as a result of searching activities, searching costs are assumed as increasing (i.e. $\alpha \in(0,1)$ ). Now assume that System (2) has a solution, and let us call the processes operated at time $t$ in this solution as the position at time $t$. The number of possible positions is finite due to the fact the number of processes is finite. Therefore, at least one position is replicated for infinite time. Since the amounts of resources are given and the searching costs are increasing, meaning that searching processes cannot be operated in perpetuity. In

\footnotetext{
${ }^{5}$ For an elaboration on the complexities presented from considering pure joint production, readers can refer to the work of Salvadori $(1982,1985)$ and others.
} 
addition, the vector of the amounts of resources utilised in each position is bounded from below, any position which is replicated for an infinite number of times either includes no processes that use exhaustible resources at all, or includes processes that use exhaustible resources together with processes that can produce the consumption vector $\gamma \delta$ without using exhaustible resources.

Therefore, we can divide a period of time that stretches from 0 to infinity into two periods, a finite period from 0 to $\tau^{\prime}$, and an infinite period from $\tau^{\prime}+1$ to infinity. This can be done on the condition that only the backstop technology is actually operated during the second period. In addition, if Assumptions 3 and 4 hold, the period from $\tau^{\prime}+1$ to infinity can be divided into two periods, a finite period from $\tau^{\prime}+1$ to $\tau^{\prime \prime}$ and an infinite period from $\tau^{\prime \prime}+1$ to infinity, on condition that, in the second period the following equations hold.

$$
\begin{aligned}
\boldsymbol{p}_{t} & =\mathbf{A}^{* t-\tau^{\prime \prime}} \boldsymbol{p}_{\tau^{\prime \prime}} \\
\boldsymbol{y}_{t} & =\boldsymbol{y}_{\tau^{\prime \prime}}
\end{aligned}
$$

where $\mathbf{A}^{*}=\left[\hat{\mathbf{B}}-\hat{\boldsymbol{l}}_{1} \boldsymbol{w}^{\mathrm{T}}\right]^{-1} \hat{\mathbf{A}}$. In other words, after $\tau^{\prime \prime}$, the cost-minimising backstop processes are operated.

The logic presented above indicates that an investigation on the following system as a preliminary step to analysing System (2).

$$
\begin{aligned}
& \left(\mathbf{B}-\boldsymbol{l}_{1} \boldsymbol{w}^{\mathrm{T}}\right) \boldsymbol{p}_{t+1} \leqq \mathbf{A} \boldsymbol{p}_{t}+\mathbf{C} \boldsymbol{y}_{t}+\mathbf{C} \boldsymbol{q}_{t} \quad 0 \leq t \leq \theta-1 \\
& \boldsymbol{x}_{t+1}^{\mathrm{T}}\left(\mathbf{B}-\boldsymbol{l}_{1} \boldsymbol{w}^{\mathrm{T}}\right) \boldsymbol{p}_{t+1}=\boldsymbol{x}_{t+1}^{\mathrm{T}}\left(\mathbf{A} \boldsymbol{p}_{t}+\mathbf{C} \boldsymbol{y}_{t}+\mathbf{C} \boldsymbol{q}_{t}\right) \quad 0 \leq t \leq \theta-1 \\
& \boldsymbol{y}_{t+1} \leqq \boldsymbol{y}_{t} \quad 0 \leq t \leq \theta-1 \\
& \boldsymbol{z}_{t+1}^{\mathrm{T}} \boldsymbol{y}_{t+1}=\boldsymbol{z}_{t+1}^{\mathrm{T}} \boldsymbol{y}_{t} \quad 0 \leq t \leq \theta-1 \\
& \mathbf{D}_{t+1} \boldsymbol{y}_{t+1} \leqq \mathbf{F} \boldsymbol{p}_{t}+l_{2} \boldsymbol{w}^{\mathrm{T}} \boldsymbol{p}_{t+1} \quad 0 \leq t \leq \theta-1 \\
& \boldsymbol{s}_{t+1}^{\mathrm{T}} \mathbf{D}_{t+1} \boldsymbol{y}_{t+1}=\boldsymbol{s}_{t+1}^{\mathrm{T}}\left[\mathbf{F} \boldsymbol{p}_{t}+\boldsymbol{l}_{2} \boldsymbol{w}^{\mathrm{T}} \boldsymbol{p}_{t+1}\right] \quad 0 \leq t \leq \theta-1 \\
& \boldsymbol{v}^{\mathrm{T}} \geqq \boldsymbol{x}_{1}^{\mathrm{T}} \mathbf{A}+\gamma \boldsymbol{\delta}^{\mathrm{T}}+\boldsymbol{s}_{1}^{\mathrm{T}} \mathbf{F} \\
& \boldsymbol{v}^{\mathrm{T}} \boldsymbol{p}_{0}=\left(\boldsymbol{x}_{1}^{\mathrm{T}} \mathbf{A}+\gamma \boldsymbol{\delta}^{\mathrm{T}}+\boldsymbol{s}_{1}^{\mathrm{T}} \mathbf{F}\right) \boldsymbol{p}_{0} \\
& \boldsymbol{x}_{t+1}^{\mathrm{T}}\left(\mathbf{B}-\boldsymbol{l}_{1} \boldsymbol{w}^{\mathrm{T}}\right)-\boldsymbol{s}_{t+1}^{\mathrm{T}} \boldsymbol{l}_{2} \boldsymbol{w}^{\mathrm{T}} \geqq \boldsymbol{x}_{t+2}^{\mathrm{T}} \mathbf{A}+\gamma \boldsymbol{\delta}^{\mathrm{T}}+\boldsymbol{s}_{t+2}^{\mathrm{T}} \mathbf{F} \quad 0 \leq t \leq \theta-2 \\
& {\left[\boldsymbol{x}_{t+1}^{\mathrm{T}}\left(\mathbf{B}-\boldsymbol{l}_{1} \boldsymbol{w}^{\mathrm{T}}\right)-\boldsymbol{s}_{t+1}^{\mathrm{T}} \boldsymbol{l}_{2} \boldsymbol{w}^{\mathrm{T}}\right] \boldsymbol{p}_{t+1}=\left(\boldsymbol{x}_{t+2}^{\mathrm{T}} \mathbf{A}+\gamma \boldsymbol{\delta}^{\mathrm{T}}+\boldsymbol{s}_{t+2}^{\mathrm{T}} \mathbf{F}\right) \boldsymbol{p}_{t+1} \quad 0 \leq t \leq \theta-2}
\end{aligned}
$$




$$
\begin{aligned}
& \boldsymbol{x}_{\theta}^{\mathrm{T}}\left(\mathbf{B}-\boldsymbol{l}_{1} \boldsymbol{w}^{\mathrm{T}}\right) \geqq \gamma \boldsymbol{\delta}^{\mathrm{T}}+\gamma \boldsymbol{\delta}^{\mathrm{T}}\left(\mathbf{I}-\mathbf{A}^{*}\right)^{-1} \mathbf{A}^{*} \\
& \boldsymbol{x}_{\theta}^{\mathrm{T}}\left(\mathbf{B}-\boldsymbol{l}_{1} \boldsymbol{w}^{\mathrm{T}}\right) \boldsymbol{p}_{\theta}=\left[\gamma \boldsymbol{\delta}^{\mathrm{T}}+\gamma \boldsymbol{\delta}^{\mathrm{T}}\left(\mathbf{I}-\mathbf{A}^{*}\right)^{-1} \mathbf{A}^{*}\right] \boldsymbol{p}_{\theta} \\
& \overline{\boldsymbol{z}}^{\mathrm{T}} \geqq \boldsymbol{x}_{1}^{\mathrm{T}} \mathbf{C}+\boldsymbol{z}_{1}^{\mathrm{T}} \\
& \overline{\boldsymbol{z}}^{\mathrm{T}} \boldsymbol{y}_{0}=\left(\boldsymbol{x}_{1}^{\mathrm{T}} \mathbf{C}+\boldsymbol{z}_{1}^{\mathrm{T}}\right) \boldsymbol{y}_{0} \\
& \boldsymbol{z}_{t}^{\mathrm{T}}+\boldsymbol{s}_{t}^{\mathrm{T}} \mathbf{D}_{t} \geqq \boldsymbol{x}_{t+1}^{\mathrm{T}} \mathbf{C}+\boldsymbol{z}_{t+1}^{\mathrm{T}} \quad 1 \leq t \leq \theta-1 \\
& \left(\boldsymbol{z}_{t}^{\mathrm{T}}+\boldsymbol{s}_{t}^{\mathrm{T}} \mathbf{D}_{t}\right) \boldsymbol{y}_{t}=\left(\boldsymbol{x}_{t+1}^{\mathrm{T}} \mathbf{C}+\boldsymbol{z}_{t+1}^{\mathrm{T}}\right) \boldsymbol{y}_{t} \quad 1 \leq t \leq \theta-1 \\
& \boldsymbol{x}_{t+1}^{\mathrm{T}} \mathbf{C} \leqq \boldsymbol{h}^{\mathrm{T}} \quad 0 \leq t \leq \theta \\
& \boldsymbol{x}_{t+1}^{\mathrm{T}} \boldsymbol{C} \boldsymbol{q}_{t}=\boldsymbol{h}^{\mathrm{T}} \boldsymbol{q}_{t} \quad 0 \leq t \leq \theta \\
& \sum_{t=0}^{\theta-1} \boldsymbol{\delta}^{\mathrm{T}} \boldsymbol{p}_{t}+\sum_{t=\theta}^{\infty} \boldsymbol{\delta}^{\mathrm{T}} \mathbf{A}^{* t-\theta} \boldsymbol{p}_{\theta}=1 \\
& \boldsymbol{p}_{t} \geqq \mathbf{0}, \quad \boldsymbol{y}_{t} \geqq \mathbf{0}, \quad \boldsymbol{q}_{t} \geqq \mathbf{0} \quad 0 \leq t \leq \theta \\
& z_{t} \geqq \mathbf{0}, \quad \boldsymbol{x}_{t} \geqq \mathbf{0}, \quad \boldsymbol{s}_{t} \geqq \mathbf{0}, \quad 1 \leq t \leq \theta \\
& \gamma>0
\end{aligned}
$$

In system (6), $\theta$ is a positive natural number. The above system can be considered as consisting of the first $\theta$ steps of system (2), on condition that $\boldsymbol{x}_{\theta+1}=\gamma \overline{\boldsymbol{x}}$, meaning that at time at time $\theta+1$, the cost-minimising backstop processes are operated and that the intensities are such that the cost-minimising backstop processes produce $\gamma$ units of consumption vector $\boldsymbol{\delta}$. Therefore $\boldsymbol{x}_{\theta+1}^{\mathrm{T}} \mathbf{A}=\gamma \boldsymbol{\delta}^{\mathrm{T}}\left(\mathbf{I}-\mathbf{A}^{*}\right)^{-1} \mathbf{A}^{* 6}$ and prices for $t>\theta$ are as follows.

$$
\boldsymbol{p}_{t}=\mathbf{A}^{* t-\theta} \boldsymbol{p}_{\theta}
$$

Resource-searching processes cannot be operated in perpetuity. There is no harm in assuming that searching activities stop before the backstop technology is used. ${ }^{7}$ Therefore, we have $s_{t}=0$ for all $t \geq \theta$.

\footnotetext{
${ }^{6}$ Let $\hat{\boldsymbol{x}}^{*}$ serve as the intensity vector corresponding to $\left(\hat{\mathbf{A}}, \mathbf{0}, \hat{\boldsymbol{I}}_{1}, \hat{\mathbf{B}}\right) \cdot \overline{\boldsymbol{x}}^{\top} \mathbf{A}=\hat{\boldsymbol{x}}^{* \top} \hat{\mathbf{A}}$, and $\hat{\mathbf{A}}=\left(\hat{\mathbf{B}}-\hat{\boldsymbol{I}}_{1} \boldsymbol{w}^{\top}\right) \mathbf{A}^{*}$$$
\hat{\boldsymbol{x}}^{*}\left(\hat{\mathbf{B}}-\hat{\boldsymbol{l}}_{1} \boldsymbol{w}^{\top}-\hat{\mathbf{A}}\right)=\hat{\boldsymbol{x}}^{*}\left(\hat{\mathbf{B}}-\hat{\boldsymbol{l}}_{1} \boldsymbol{w}^{\top}\right)\left(\mathbf{I}-\mathbf{A}^{*}\right)=\boldsymbol{\delta}^{\top} .
$$$$
\hat{\boldsymbol{x}}^{*}\left(\hat{\mathbf{B}}-\hat{\boldsymbol{I}}_{1} w^{\top}\right) \mathbf{A}^{*}=\boldsymbol{\delta}^{\top}\left(\mathbf{I}-\mathbf{A}^{*}\right)^{-1} \mathbf{A}^{*} .
$$

${ }^{7}$ If this situation does not hold, then it is possible to find another larger $\theta$ such that the searching activities are halted.
} 
In what follows, a sufficient and necessary condition for the existence of solutions to System (6) is given. It can be shown that System (6) is equivalent to the following linear programming problems which are dual to each other.

(primal):

$$
\operatorname{Min} \boldsymbol{v}^{\mathrm{T}} \boldsymbol{p}_{0}+\overline{\boldsymbol{z}}^{\mathrm{T}} \boldsymbol{y}_{0}+\boldsymbol{h}^{\mathrm{T}} \sum_{t=0}^{\theta} \boldsymbol{q}_{t}
$$

s.t.

$$
\begin{aligned}
& \left(\mathbf{B}-\boldsymbol{l}_{1} \boldsymbol{w}^{\mathrm{T}}\right) \boldsymbol{p}_{t+1} \leqq \mathbf{A} \boldsymbol{p}_{t}+\mathbf{C} \boldsymbol{y}_{t}+\mathbf{C} \boldsymbol{q}_{t} \quad 0 \leq t \leq \theta-1 \\
& \boldsymbol{y}_{t+1} \leqq \boldsymbol{y}_{t} \quad 0 \leq t \leq \theta-1 \\
& \mathbf{D}_{t+1} \boldsymbol{y}_{t+1} \leqq \mathbf{F} \boldsymbol{p}_{t}+\boldsymbol{l}_{2} \boldsymbol{w}^{\mathrm{T}} \boldsymbol{p}_{t+1} \quad 0 \leq t \leq \theta-1 \\
& \sum_{t=0}^{\theta-1} \boldsymbol{\delta}^{\mathrm{T}} \boldsymbol{p}_{t}+\boldsymbol{\delta}^{\mathrm{T}}\left(\mathbf{I}-\mathbf{A}^{*}\right)^{-1} \boldsymbol{p}_{\theta}=1 \\
& \boldsymbol{p}_{t} \geqq \mathbf{0}, \quad \boldsymbol{y}_{t} \geqq \mathbf{0}, \quad \boldsymbol{q}_{t} \geqq \mathbf{0}, \quad 0 \leq t \leq \theta
\end{aligned}
$$

(dual):

$\operatorname{Max} \gamma$

s.t.

$$
\begin{aligned}
& \boldsymbol{v}^{\mathrm{T}} \geqq \boldsymbol{x}_{1}^{\mathrm{T}} \mathbf{A}+\gamma \boldsymbol{\delta}^{\mathrm{T}}+\boldsymbol{s}_{1}^{\mathrm{T}} \mathbf{F} \\
& \boldsymbol{x}_{t+1}^{\mathrm{T}}\left(\mathbf{B}-\boldsymbol{l}_{1} \boldsymbol{w}^{\mathrm{T}}\right)-\boldsymbol{s}_{t+1}^{\mathrm{T}} \boldsymbol{l}_{2} \boldsymbol{w}^{\mathrm{T}} \geqq \boldsymbol{x}_{t+2}^{\mathrm{T}} \mathbf{A}+\gamma \boldsymbol{\delta}^{\mathrm{T}}+\boldsymbol{s}_{t+2}^{\mathrm{T}} \mathbf{F} \quad 0 \leq t \leq \theta-2 \\
& \boldsymbol{x}_{\theta}^{\mathrm{T}}\left(\mathbf{B}-\boldsymbol{l}_{1} \boldsymbol{w}^{\mathrm{T}}\right) \geqq \gamma \boldsymbol{\delta}^{\mathrm{T}}+\gamma \boldsymbol{\delta}^{\mathrm{T}}\left(\mathbf{I}-\mathbf{A}^{*}\right)^{-1} \mathbf{A}^{*} \\
& \overline{\boldsymbol{z}}^{\mathrm{T}} \geqq \boldsymbol{x}_{1}^{\mathrm{T}} \mathbf{C}+\boldsymbol{z}_{1}^{\mathrm{T}} \\
& \boldsymbol{z}_{t}^{\mathrm{T}}+\boldsymbol{s}_{t}^{\mathrm{T}} \mathbf{D}_{t} \geqq \boldsymbol{x}_{t+1}^{\mathrm{T}} \mathbf{C}+\boldsymbol{z}_{t+1}^{\mathrm{T}} \quad 1 \leq t \leq \theta-1 \\
& \boldsymbol{x}_{t+1}^{\mathrm{T}} \mathbf{C} \leqq \boldsymbol{h}^{\mathrm{T}} \quad 0 \leq t \leq \theta \\
& \boldsymbol{z}_{t} \geqq \mathbf{0}, \quad \boldsymbol{x}_{t} \geqq \mathbf{0}, \quad \boldsymbol{s}_{t} \geqq \mathbf{0}, \quad 1 \leq t \leq \theta
\end{aligned}
$$

Lemma 1 If a backstop technology is available, System (6) has a solution for $\theta=\theta^{\prime}$, if, and only if, the following Assumption 5 holds. 
Assumption 5 There are three finite sequences $\left\{\boldsymbol{x}_{t}\right\},\left\{\boldsymbol{s}_{t}\right\},\left\{\boldsymbol{z}_{t}\right\}, 1 \leq t \leq \theta$, and a real number $\gamma$, such that system (8) holds for $\theta=\theta^{\prime}$.

The inclusion of Assumption 5 means that for $\theta=\theta^{\prime}$ there exist intensities $\left\{\boldsymbol{x}_{t}\right\},\left\{\boldsymbol{s}_{t}\right\}$ and amounts of resources $\left\{z_{t}\right\}$ such that the economy is able to reproduce itself under the capacity constraints on extraction.

The proof of Lemma 1 is similar to that found in the model of Kurz and Salvadori (1995, Chap. 12, Sect. 4.), which is not included here.

After showing the condition such that the first $\theta$ steps of system (2) have a solution, then the issue moves to how paths of quantities $\left(\left\{\boldsymbol{x}_{t}\right\},\left\{\boldsymbol{s}_{t}\right\}\right.$ and $\left.\left\{\boldsymbol{z}_{t}\right\}\right)$ as well as prices $\left(\left\{\boldsymbol{p}_{t}\right\}\right.$, $\left.\left\{\boldsymbol{y}_{t}\right\},\left\{\boldsymbol{q}_{t}\right\}\right)$ manifest so that System (2) can sustain itself?

If a solution can be found for a $\theta=\theta^{\prime}$, then a solution for $\theta=\theta^{\prime \prime}$ where $\theta^{\prime \prime} \geq \theta^{\prime}$, can be found as well. This is illustrated by the following lemma.

Lemma 2 If System (6) has a solution for $\theta=\theta^{\prime}$, then it has a solution for $\theta=\theta^{\prime \prime}$, each $\theta^{\prime \prime} \geq \theta^{\prime}$

The proof of Lemma 2 is similar to the proof for Proposition 2 found in the work of Kurz and Salvadori (2000b), which is also not included here.

Now it is assumed that there is a natural number $\theta^{\prime}$, such that Assumption 5 holds. Then for each $\theta \geq \theta^{\prime}$ the maximum of the dual problem exists and is positive. We refer to this maximum as $\gamma_{\theta}$. For each $\theta \geq \theta^{\prime}$, six sequences $\left\{\boldsymbol{x}_{t \theta}\right\},\left\{\boldsymbol{z}_{t \theta}\right\},\left\{\boldsymbol{s}_{t \theta}\right\},\left\{\boldsymbol{p}_{t \theta}\right\},\left\{\boldsymbol{y}_{t \theta}\right\}$ and $\left\{\boldsymbol{q}_{t \theta}\right\}$ are defined as follows. For $t \leq \theta$, the sequences $\boldsymbol{p}_{t \theta}, \boldsymbol{y}_{t \theta}$ and $\boldsymbol{q}_{t \theta}$ equal the corresponding elements of the optimal solution of the primal problem, and $\boldsymbol{x}_{t \theta}, z_{t \theta}$ and $\boldsymbol{s}_{t \theta}$ equal the corresponding elements of the optimal solution of the dual problem, and for $t \geq \theta$ :

$$
\begin{aligned}
\boldsymbol{p}_{t \theta} & =\mathbf{A}^{* t-\theta} \boldsymbol{p}_{\theta \theta} \\
\boldsymbol{y}_{t \theta} & =\boldsymbol{y}_{\theta \theta} \\
\boldsymbol{q}_{t \theta} & =\boldsymbol{q}_{\theta \theta} \\
\boldsymbol{x}_{t \theta} & =\gamma_{\theta} \overline{\boldsymbol{x}} \\
\boldsymbol{z}_{t \theta} & =\boldsymbol{z}_{\theta \theta} \\
\boldsymbol{s}_{t \theta} & =\mathbf{0}
\end{aligned}
$$

Based on the analysis provided above, a solution to System (2) can be obtained.

Theorem 1 The sequences $\left\{\boldsymbol{p}_{t}^{*}\right\},\left\{\boldsymbol{y}_{t}^{*}\right\},\left\{\boldsymbol{q}_{t}^{*}\right\},\left\{\boldsymbol{x}_{t}^{*}\right\},\left\{z_{t}^{*}\right\}$ and $\left\{\boldsymbol{s}_{t}^{*}\right\}$, as well as a real number $\gamma^{*}$ defined as

$$
\begin{aligned}
& \boldsymbol{p}_{t}^{*}=\lim _{\theta \rightarrow \infty} \boldsymbol{p}_{t \theta} \\
& \boldsymbol{y}_{t}^{*}=\lim _{\theta \rightarrow \infty} \boldsymbol{y}_{t \theta} \\
& \boldsymbol{q}_{t}^{*}=\lim _{\theta \rightarrow \infty} \boldsymbol{q}_{t \theta}
\end{aligned}
$$




$$
\begin{aligned}
& \boldsymbol{x}_{t}^{*}=\lim _{\theta \rightarrow \infty} \boldsymbol{x}_{t \theta} \\
& \boldsymbol{z}_{t}^{*}=\lim _{\theta \rightarrow \infty} \boldsymbol{z}_{t \theta} \\
& \boldsymbol{s}_{t}^{*}=\lim _{\theta \rightarrow \infty} \boldsymbol{s}_{t \theta} \\
& \gamma^{*}=\lim _{\theta \rightarrow \infty} \gamma_{\theta}
\end{aligned}
$$

constitute a solution to System (2).

The proof of Theorem 1 is similar to the proof for Proposition 3 in the work of Kurz and Salvadori (2000b), which is also not included here.

\section{Discussions}

\subsection{The circumstances for the existence of constant prices}

The Hotelling rule implies that the royalties of resources have to increase at a rate that equals the rate of profit, and this seems to imply further that the prices of most, if not all, commodities are bound to change. The implication of the latter observation may lead to a belief that the classical economics, which generally focuses on the long-period position or long-period prices, lacks the insight to deal with the problem of exhaustible resources. However, such thinking is both incorrect and misleading.

The classical long-period method does not stick strictly to stationary prices. Longperiod prices change as the data which determine them change. ${ }^{8}$ In most cases these changes are sufficiently gradual and slow compared with the speed at which market prices gravitate towards the long-period, or natural prices. When this premise (the slowness of the changes of long-period prices) does not hold, given the unsatisfactory nature of the marginal approach, 'the long-period method appears to be the only acceptable one available at present' (Kurz and Salvadori 1995, p. 341). Moreover, the implication that the prices of commodities are bounded to change is not obvious nor is it necessarily true. It can be shown that under a few well-defined circumstances, the prices of commodities can remain constant when exhaustible resources exist. This will be elaborated upon further in this section.

Such circumstances have been elaborated upon in the work of Kurz and Salvadori $(2009,2011)$ as well. Firstly, the backstop technology is cost-minimising from the outset, and as such, other processes are not operated. Second, the capacity constraints on extraction are so binding that the processes that use exhaustible resources cannot produce the required consumptions alone, and the backstop technology has to be operated simultaneously. Third, for each exhaustible deposit of a resource, another with the same characteristics can be discovered, and the searching cost (in terms of labour and

\footnotetext{
${ }^{8}$ For instance, as Sraffa mentioned, when a plot of less fertile land is taken into cultivation due to an increased demand in an agricultural commodity, ' $\cdots$ the output may increase continuously, although the methods of production [hence the prices] are changed spasmodically' (Sraffa 1960, p. 88).
} 
commodities) is always the same. These circumstances can be represented by this study's model.

\subsection{The backstop technology is cost-minimising from the beginning}

We first show a situation in which resources are too costly, to such an extent that they are neither extracted nor used. For instance, while it is known that there are plenty of resources in the Arctic Circle, current technology does not allow for their practical extraction due to high costs or other technological issues. In these kinds of situations, the processes of extracting and using resources are dominated by the backstop technology. Such a situation can be represented as follows.

$$
\tilde{\mathbf{B}} \boldsymbol{p}^{*}<\tilde{\mathbf{A}} \boldsymbol{p}^{*}\left(1+r^{*}\right)+\tilde{\boldsymbol{l}}_{1} \boldsymbol{w}^{\mathrm{T}} \boldsymbol{p}^{*}
$$

where $\boldsymbol{p}^{*}$ and $r^{*}$ are defined by Assumption 2. Inequality (11) means that the processes using exhaustible resources are not profitable at the rate of profit and prices determined by the cost-minimising backstop processes even if the royalties and rents are zero. Hence, in such a situation, no resources will be extracted or used, and the backstop technology is resorted to immediately. An example is provided by Kurz and Salvadori (2011). Since the backstop technology converges to the backstop cost-minimising processes, the long-period prices (as determined by the latter) are constant. It should again be emphasised that 'whether some substance in the ground is, or is not, a resource cannot generally be defined independently of the rate of profits and the technical alternatives that are available in the system' (Kurz and Salvadori 2011, p. 45, emphasis in original).

\subsection{The backstop technology is operated from the beginning due to capacity constraints}

In reality, extraction at a resource deposit is typically constrained, and in order to satisfy demands for consumption, mines of different unit costs in exploitation, or of different fertilities have to be operated simultaneously. This fact is well observed by the classical economists, particularly Ricardo. It is also possible that all resource mines which are profitable to extract are all operated but that capacity constraints on extractions are so binding that fulfilling the demands for consumption cannot be achieved by operating only processes that use exhaustible resources. As a consequence, the backstop technology has to be operated simultaneously.

In such a situation, even though the amount of exhaustible resources decreases and the Hotelling rule applies to the royalties of resources, the prices of commodities remain constant due to the fact that the resource owners are not only paid royalties, but also rents, and to the fact that the royalties and rents of resources change in the opposite way such that their summations are constant. This situation is represented as follows.

Assuming that Assumption 5 holds and that a solution to system (2) exists, the following system holds.

$$
\begin{aligned}
& \boldsymbol{s}_{t}^{* T} \mathbf{D}_{t}<\boldsymbol{x}_{t+1}^{* T} \mathbf{C} \\
& \boldsymbol{x}_{t+1}^{* T} \mathbf{C}=\boldsymbol{h}^{T}
\end{aligned}
$$




$$
\tilde{\boldsymbol{x}}_{t+1}^{* T}\left(\tilde{\mathbf{B}}-\tilde{\boldsymbol{l}}_{1} \boldsymbol{w}^{\mathrm{T}}\right)-\boldsymbol{s}_{t+1}^{* T} \boldsymbol{l}_{2} \boldsymbol{w}^{\mathrm{T}}<\tilde{\boldsymbol{x}}_{t+2}^{* T} \tilde{\mathbf{A}}+\gamma^{*} \boldsymbol{\delta}^{\mathrm{T}}+\boldsymbol{s}_{t+2}^{* T} \mathbf{F}
$$

$\left(\tilde{\mathbf{A}}, \tilde{\mathbf{C}}, \tilde{\boldsymbol{l}}_{1}, \tilde{\mathbf{B}}\right)$ are processes that use exhaustible resources while $\tilde{\boldsymbol{x}}^{*}$ denotes the corresponding intensity vector. Inequality (12a) means that the resources discovered from the searching activities cannot satisfy the resource consumption needs. Hence, the amount of resources remaining in the ground decreases. Equation (12b) means that the extraction of the resources reaches capacity constraints. Inequality (12c) means that the processes using exhaustible resources are not able to produce the required consumptions, even though the extraction reach its limits. Hence, the backstop technology has to be operated simultaneously.

Since backstop technology is assumed to converge to the cost-minimising backstop processes, it is assumed that at some time $\theta_{1},\left(\hat{\mathbf{A}}, \mathbf{0}, \hat{\boldsymbol{l}}_{1}, \hat{\mathbf{B}}\right)$ is operated and the corresponding intensities are $\hat{\boldsymbol{x}}^{*}$. It is also assumed that searching activities will halt before $\theta_{1}$. Therefore, after time $\theta_{1}$, the path of prices $\left\{\boldsymbol{p}_{t}\right\}$ becomes a time-invariant sequence $\left\{\boldsymbol{p}^{*}\right\}$, and Equations (1a) and (1b) are replaced by the following.

$$
\begin{aligned}
& \mathbf{B} \boldsymbol{p}^{*} \leqq\left(\mathbf{A} \boldsymbol{p}^{*}+\mathbf{C} \boldsymbol{y}_{t}+\mathbf{C} \boldsymbol{q}_{t}\right)\left(1+r^{*}\right)+\boldsymbol{l}_{1} \boldsymbol{w}^{\mathrm{T}} \boldsymbol{p}^{*} \quad t \geq \theta_{1} \\
& \boldsymbol{x}_{t+1}^{* T} \mathbf{B} \boldsymbol{p}^{*}=\boldsymbol{x}_{t+1}^{* T}\left[\left(\mathbf{A} \boldsymbol{p}^{*}+\mathbf{C} \boldsymbol{y}_{t}+\mathbf{C} \boldsymbol{q}_{t}\right)\left(1+r^{*}\right)+\boldsymbol{l}_{1} \boldsymbol{w}^{\mathrm{T}} \boldsymbol{p}^{*}\right] \quad t \geq \theta_{1}
\end{aligned}
$$

where $\boldsymbol{p}^{*}$ and $r^{*}$ are defined by Assumption 2. Let $\left(\mathbf{A}_{t}, \mathbf{C}_{t}, \boldsymbol{l}_{1 t}, \mathbf{B}_{t}\right)$ represent the processes that are actually operated at time $t\left(t \geq \theta_{1}\right)$, consequently we get the following equation.

$$
\mathbf{B}_{t} \boldsymbol{p}^{*}=\left(\mathbf{A}_{t} \boldsymbol{p}^{*}+\mathbf{C}_{t} \boldsymbol{y}_{t}^{*}+\mathbf{C}_{t} \boldsymbol{q}_{t}^{*}\right)\left(1+r^{*}\right)+\boldsymbol{l}_{1 t} \boldsymbol{w}^{\mathrm{T}} \boldsymbol{p}^{*} \quad t \geq \theta_{1}
$$

From Eq. (14) it can be seen that $\left(\boldsymbol{y}_{t}^{*}+\boldsymbol{q}_{t}^{*}\right)$ is constant, and even though the royalties increase according to the Hotelling rule, the rents move in the opposite way, such that their summations are constant.

The paths of royalties and rents are derived from the following procedure. Assuming that the resources will become exhausted at time $\theta_{2}$, then the amount of resources will be very small such that:

$$
\boldsymbol{h}^{\mathrm{T}}>\boldsymbol{z}_{\theta_{2}-1}^{\mathrm{T}}-\boldsymbol{z}_{\theta_{2}}^{\mathrm{T}} \geqq \tilde{\boldsymbol{x}}_{\theta_{2}}^{*} \tilde{\mathbf{C}}
$$

Therefore at time $\theta_{2}$, rents are zero as mines are not being fully exploited: $\boldsymbol{q}_{\theta_{2}}^{*}=\mathbf{0} . \boldsymbol{y}_{\theta_{2}}^{*}$ is derived as the differential rents between backstop technology and the processes using exhaustible resources. Taking $\boldsymbol{y}_{\theta}^{*}$ as given, the royalties at time $t$ can be determined via the Hotelling rule through backward induction.

$$
\boldsymbol{y}_{t}^{*}=\left(1+r^{*}\right)^{t-\theta_{2}} \boldsymbol{y}_{\theta_{2}}^{*} \quad \theta_{1} \leq t \leq \theta_{2}
$$

Taking $\boldsymbol{y}_{t}^{*}$ as given thereafter, rents $\boldsymbol{q}_{t}^{*}$ at each time $t$ can be determined from Eq. (14). 


\subsection{Resources are'reproduced' by labour and commodities}

As stated in the previous sections of this paper, Ricardo's analysis of exhaustible resources is relevant to an economic environment in which there exist capacity constraints on extractions and searching activities whose costs in terms of commodities and labour are constant. In such an environment, resources are not exactly exhaustible (at least in some periods), and resources can be discovered or 'reproduced' by labour and other commodities. ${ }^{9}$ In such an economic environment, a storage of resources is not profitable, and System (2) is simplified as follows: ${ }^{10}$

$$
\begin{aligned}
& \mathbf{B} \boldsymbol{p}_{t+1} \leqq \mathbf{A} \boldsymbol{p}_{t}+\mathbf{C} \boldsymbol{y}_{t}+\mathbf{C} \boldsymbol{q}_{t}+\boldsymbol{l}_{1} \boldsymbol{w}^{\mathrm{T}} \boldsymbol{p}_{t+1} \\
& \boldsymbol{x}_{t+1}^{\mathrm{T}} \mathbf{B} \boldsymbol{p}_{t+1}=\boldsymbol{x}_{t+1}^{\mathrm{T}}\left(\mathbf{A} \boldsymbol{p}_{t}+\mathbf{C} \boldsymbol{y}_{t}+\mathbf{C} \boldsymbol{q}_{t}+\boldsymbol{l}_{1} \boldsymbol{w}^{\mathrm{T}} \boldsymbol{p}_{t+1}\right) \\
& \mathbf{D} \boldsymbol{y}_{t+1} \leqq \mathbf{F} \boldsymbol{p}_{t}+\boldsymbol{l}_{2} \boldsymbol{w}^{\mathrm{T}} \boldsymbol{p}_{t+1} \\
& \boldsymbol{s}_{t+1}^{\mathrm{T}} \mathbf{D} \boldsymbol{y}_{t+1}=\boldsymbol{s}_{t+1}^{\mathrm{T}}\left(\mathbf{F} \boldsymbol{p}_{t}+\boldsymbol{l}_{2} \boldsymbol{w}^{\mathrm{T}} \boldsymbol{p}_{t+1}\right) \\
& \boldsymbol{v}^{\mathrm{T}} \geqq \boldsymbol{x}_{1}^{\mathrm{T}} \mathbf{A}+\gamma \boldsymbol{\delta}^{\mathrm{T}}+\boldsymbol{s}_{1}^{\mathrm{T}} \mathbf{F} \\
& \boldsymbol{v}^{\mathrm{T}} \boldsymbol{p}_{0}=\left(\boldsymbol{x}_{1}^{\mathrm{T}} \mathbf{A}+\gamma \boldsymbol{\delta}^{\mathrm{T}}+\boldsymbol{s}_{1}^{\mathrm{T}} \mathbf{F}\right) \boldsymbol{p}_{0} \\
& \boldsymbol{x}_{t+1}^{\mathrm{T}}\left(\mathbf{B}-\boldsymbol{l}_{1} \boldsymbol{w}^{\mathrm{T}}\right)-\boldsymbol{s}_{t+1}^{\mathrm{T}} \boldsymbol{l}_{2} \boldsymbol{w}^{\mathrm{T}} \geqq \boldsymbol{x}_{t+2}^{\mathrm{T}} \mathbf{A}+\gamma \boldsymbol{\delta}^{\mathrm{T}}+\boldsymbol{s}_{t+2}^{\mathrm{T}} \mathbf{F} \\
& {\left[\boldsymbol{x}_{t+1}^{\mathrm{T}}\left(\mathbf{B}-\boldsymbol{l}_{1} \boldsymbol{w}^{\mathrm{T}}\right)-\boldsymbol{s}_{t+1}^{\mathrm{T}} \boldsymbol{l}_{2} \boldsymbol{w}^{\mathrm{T}}\right] \boldsymbol{p}_{t+1}=\left(\boldsymbol{x}_{t+2}^{\mathrm{T}} \mathrm{A}+\gamma \boldsymbol{\delta}^{\mathrm{T}}+\boldsymbol{s}_{t+2}^{\mathrm{T}} \mathbf{F}\right) \boldsymbol{p}_{t+1}} \\
& \boldsymbol{z}_{0}^{\mathrm{T}} \geqq \boldsymbol{x}_{1}^{\mathrm{T}} \mathbf{C} \\
& z_{0}^{\mathrm{T}} \boldsymbol{y}_{0}=\boldsymbol{x}_{1}^{\mathrm{T}} \mathbf{C} \boldsymbol{y}_{0} \\
& \boldsymbol{s}_{t}^{\mathrm{T}} \mathbf{D} \geqq \boldsymbol{x}_{t+1}^{\mathrm{T}} \mathbf{C} \\
& \boldsymbol{s}_{t}^{\mathrm{T}} \mathbf{D} \boldsymbol{y}_{t}=\boldsymbol{x}_{t+1}^{\mathrm{T}} \mathbf{C} \boldsymbol{y}_{t} \\
& \boldsymbol{x}_{t+1}^{\mathrm{T}} \mathbf{C} \leqq \boldsymbol{h}^{\mathrm{T}} \\
& \boldsymbol{x}_{t+1}^{\mathrm{T}} \mathbf{C} \boldsymbol{q}_{t}=\boldsymbol{h}^{\mathrm{T}} \boldsymbol{q}_{t}
\end{aligned}
$$

\footnotetext{
9 This was pointed out by Sraffa in his unpublished Paper and Correspondence, see Kurz and Salvadori (2000b, p. 169).

10 There exist differences between the model presented in this sub-section and the models of renewable resources built by Kurz and Salvadori (1995, Ch. 12, Sec. 3) as well as Erreygers (2015). In the present model, the costs of 'producing' resources are always constant, and there exists capacity constraint on extraction in each resource mine.
} 


$$
\begin{aligned}
& \sum_{t=0}^{\infty} \delta^{\mathrm{T}} \boldsymbol{p}_{t}=1 \\
& \gamma>0, \quad \boldsymbol{p}_{t} \geqq \mathbf{0}, \quad \boldsymbol{y}_{t} \geqq \mathbf{0}, \quad \boldsymbol{q}_{t} \geqq \mathbf{0}, \quad \boldsymbol{x}_{t} \geqq \mathbf{0}, \quad \boldsymbol{s}_{t} \geqq \mathbf{0}
\end{aligned}
$$

Two questions arise here. First, on what conditions are there stationary prices in System (17)? Second, what condition guarantees that the sequences of price solutions to System (17) converge to stationary prices? Discussion of the second question (relevant to the convergence question) is beyond the scope of this paper. Rather, focus will be placed on the first question. Therefore it is assumed that the sequences of price solutions converge to the stationary prices so long as the latter exist. The following assumption and theorem provide the answer to the first question.

Assumption 6 There exist vectors $\hat{\boldsymbol{x}}, \hat{\boldsymbol{s}}$ and $\hat{\gamma}$ such that the following inequalities hold:

$$
\begin{aligned}
& \hat{\boldsymbol{x}}^{\mathrm{T}}\left(\mathbf{B}-\boldsymbol{l}_{1} \boldsymbol{w}^{\mathrm{T}}\right)-\hat{\boldsymbol{s}}^{\mathrm{T}} \boldsymbol{l}_{2} \boldsymbol{w}^{\mathrm{T}} \geqq \hat{\boldsymbol{x}}^{\mathrm{T}} \mathbf{A}+\hat{\boldsymbol{s}}^{\mathrm{T}} \mathbf{F}+\hat{\gamma} \boldsymbol{\delta}^{\mathrm{T}} \\
& \hat{\boldsymbol{s}}^{\mathrm{T}} \mathbf{D} \geqq \hat{\boldsymbol{x}}^{\mathrm{T}} \mathbf{C} \\
& \boldsymbol{h}^{\mathrm{T}} \geqq \hat{\boldsymbol{x}}^{\mathrm{T}} \mathbf{C}
\end{aligned}
$$

Assumption 6 means that the technology is sufficiently productive that, at intensities $\hat{\boldsymbol{x}}$ and $\hat{\boldsymbol{s}}$, the economy is able to reproduce itself even under the capacity constraints of extraction.

Theorem 2 If Assumption 6 holds, there exists a solution $\left(\boldsymbol{p}^{*}, \boldsymbol{y}^{*}, \boldsymbol{q}^{*}, \boldsymbol{x}^{*}, \boldsymbol{s}^{*}, \gamma^{*}\right)$ to the following system:

$$
\begin{aligned}
& \mathbf{B} \boldsymbol{p} \leqq \mathbf{A} \boldsymbol{p}+\mathbf{C} \boldsymbol{y}+\mathbf{C} \boldsymbol{q}+\boldsymbol{l}_{1} \boldsymbol{w}^{\mathrm{T}} \boldsymbol{p} \\
& \boldsymbol{x}^{\mathrm{T}} \mathbf{B} \boldsymbol{p}=\boldsymbol{x}^{\mathrm{T}}\left(\mathbf{A} \boldsymbol{p}+\mathbf{C} \boldsymbol{y}+\mathbf{C} \boldsymbol{q}+\boldsymbol{l}_{1} \boldsymbol{w}^{\mathrm{T}} \boldsymbol{p}\right) \\
& \mathbf{D} \boldsymbol{y} \leqq \mathbf{F} \boldsymbol{p}+\boldsymbol{l}_{2} \boldsymbol{w}^{\mathrm{T}} \boldsymbol{p} \\
& \boldsymbol{s}^{\mathrm{T}} \mathbf{D} \boldsymbol{y}=\boldsymbol{s}^{\mathrm{T}}\left(\mathbf{F} \boldsymbol{p}+\boldsymbol{l}_{2} \boldsymbol{w}^{\mathrm{T}} \boldsymbol{p}\right) \\
& \boldsymbol{x}^{\mathrm{T}}\left(\mathbf{B}-\boldsymbol{l}_{1} \boldsymbol{w}^{\mathrm{T}}\right)-\boldsymbol{s}^{\mathrm{T}} \boldsymbol{l}_{2} \boldsymbol{w}^{\mathrm{T}} \geqq \boldsymbol{x}^{\mathrm{T}} \mathbf{A}+\boldsymbol{s}^{\mathrm{T}} \mathbf{F}+\gamma \boldsymbol{\delta}^{\mathrm{T}} \\
& {\left[\boldsymbol{x}^{\mathrm{T}}\left(\mathbf{B}-\boldsymbol{l}_{1} \boldsymbol{w}^{\mathrm{T}}\right)-\boldsymbol{s}^{\mathrm{T}} \boldsymbol{l}_{2} \boldsymbol{w}^{\mathrm{T}}\right] \boldsymbol{p}=\left(\boldsymbol{x}^{\mathrm{T}} \mathbf{A}+\boldsymbol{s}^{\mathrm{T}} \mathbf{F}+\gamma \boldsymbol{\delta}^{\mathrm{T}}\right) \boldsymbol{p}}
\end{aligned}
$$




$$
\begin{aligned}
& \boldsymbol{s}^{\mathrm{T}} \mathbf{D} \geqq \boldsymbol{x}^{\mathrm{T}} \mathbf{C} \\
& \boldsymbol{s}^{\mathrm{T}} \mathbf{D} \boldsymbol{y}=\boldsymbol{x}^{\mathrm{T}} \mathbf{C} \boldsymbol{y} \\
& \boldsymbol{x}^{\mathrm{T}} \mathbf{C} \leqq \boldsymbol{h}^{\mathrm{T}} \\
& \boldsymbol{x}^{\mathrm{T}} \mathbf{C} \boldsymbol{q}=\boldsymbol{h}^{\mathrm{T}} \boldsymbol{q} \\
& \boldsymbol{\delta}^{\mathrm{T}} \boldsymbol{p}=1 \\
& \gamma>0, \quad \boldsymbol{p} \geqq \mathbf{0}, \quad \boldsymbol{y} \geqq \mathbf{0}, \quad \boldsymbol{q} \geqq \mathbf{0}, \quad \boldsymbol{x} \geqq \mathbf{0}, \quad \boldsymbol{s} \geqq \mathbf{0}
\end{aligned}
$$

Note that the proof that Theorem 2 is similar to that of Lemma 1 is omitted here.

It is also interesting to consider Theorem 2 and System (19) further. First, if in system (19) the capacity constraints on extraction are not binding in System (19) (i.e. $\boldsymbol{h}$ is large enough such that Inequality (19i) always holds as a strict inequality), then the model becomes similar to the fixed capital model, and the resources can be treated as machines (suggested by Kurz and Salvadori 1995, Ch. 12). Specifically, the idea here is that the searching processes produce 1-year-old machines, and that the other processes use these 1-year-old machines to produce other commodities. Second, the difference between the rent theory of land and System (19) is that the searching activities require both commodities and labour inputs, or that resources are 'produced' by labour and commodities. If these inputs are negligible, Inequality (19c) and Eq. (19d) are not valid, then the model falls into the land model found in the work of Kurz and Salvadori (1995, Ch. 10).

\section{Conclusions}

This study built an exhaustible resources model that seeks to achieve a potential reconciliation between Ricardo and Hotelling using a dynamic input-output model with classical features. In this model, there are both resource-searching activities and capacity constraints on extraction. Additionally, three types of property incomes (profits, royalties, and rents) were distinguished explicitly. The dynamics of quantity and price were discussed as well.

Based on several assumptions made for the study's model, a sufficient and necessary condition was given for the paths of endogenous variables, which are prices of commodities, royalties, rents, intensities of commodity production and resource-searching processes, as well as the amounts of exhaustible resources at each time. Following the work of Kurz and Salvadori $(2009,2011)$, this study also discussed the circumstances for the existence of constant prices based on the model presented.

It should be re-emphasised that the classical theory is not barren in dealing with exhaustible resources, and that the analyses by the classical economists, especially by Ricardo are not inferior to but rather complementary to Hotelling's. Both ideas can be incorporated into a single framework, and both are helpful in improving our understanding of the problems of exhaustible resources. 


\section{Authors' contributions}

The author has contributed in designing the research and drafting the manuscript. He has given final approval of the version to be published. The author read and approved the final manuscript.

\section{Acknowledgements}

I am deeply indebted to Professor Neri Salvadori for his inspiration, guidance and invaluable comments during the writing of this paper. An earlier version of this paper was presented at the Ph.D. annual meeting of the Department of Economics and Statistics at University of Siena as well as at the Fifth Graz Schumpeter Summer School of University of Graz. I would like to thank all the participants involved, most especially Professor F. Petri, Professor H. D. Kurz, Professor E. Bellino, Professor S. D'Alessandro, as well as two anonymous referees for their very helpful comments. The usual disclaimer applies.

\section{Competing interests}

The author declares that he has no competing interests.

Ethics approval and consent to participate

Not applicable.

Funding

This paper is a project funded by China Postdoctoral Science Foundation.

\section{Publisher's Note}

Springer Nature remains neutral with regard to jurisdictional claims in published maps and institutional affiliations.

Received: 12 November 2017 Accepted: 26 April 2018

Published online: 16 May 2018

\section{References}

Aoki M (1977) Dual stability in a Cambridge-type model. Rev Econ Stud 44:143-151

Bellino E (2011) Gravitation of market prices towards natural prices. In: Ciccone R, Gehrke C, Mongiovi G (eds) Sraffa and modern economics. Routledge, London

Bidard C, Erreygers G (2001a) The corn-guano model. Metroeconomica 52:243-253

Bidard C, Erreygers G (2001 b) Further reflections on the corn-guano model. Metroeconomica 52:254-268

Dejuan O, Lopez LA, Tobarra MN, Zafrilla J (2013) A post-Keynesian AGE model to forecast energy demand in Spain. Econ Syst Res 25:321-340

Dietzenbacher E, Stage J (2006) Mixing oil and water? Using hybrid input-output tables in a structural decomposition analysis. Econ Syst Res 18:85-95

Dobos I, Floriska A (2005) A dynamic Leontief model with non-renewable resources. Econ Syst Res 17:317-326

Dorfman R, Samuelson PA, Solow RM (1958) Linear programming and economic analysis. McGraw-Hill Book Company, New York

Duchin F, Szyld DB (1985) A dynamic input-output model with assured positive output. Metroeconomica 37:269-282

Erreygers G (2015) Renewable resources in a pong-term perspective: the corn-tuna model. Pap Polit Econ 69:97-130

Hotelling H (1931) The economics of exhaustible resources. J Polit Econ 39:137-175

Jodar L, Merello P (2010) Positive solutions of discrete dynamic Leontief input-output model with possibly singular capital matrix. Math Comput Modell 52:1081-1087

Jorgenson DW (1960) A dual stability theorem. Econometrica 28:892-899

Jorgenson DW (1961) Stability of a dynamic input-output system. Rev Econ Stud 28:105-116

Kagawa S, Inamura H (2001) A structural decomposition of energy consumption based on a hybrid rectangular inputoutput framework: Japan's case. Econ Syst Res 13:339-363

Kagawa S, Inamura H (2004) A spatial structural decomposition analysis of Chinese and Japanese energy demand: 1985-1990. Econ Syst Res 16:279-299

Karten K, Schleicher S (1999) Impact of carbon dioxide emissions reducing on the Austrian economy. Econ Syst Res $11: 245-261$

Kendrik D (1972) On the Leontief dynamic-inverse. Q J Econ 86:693-696

Kurz HD, Salvadori N (1995) Theory of production. A long-period analysis. Cambridge University Press, Cambridge

Kurz HD, Salvadori N (1997) Exhaustible resources in a dynamic input-output model with classical features. Econ Syst Res 9:235-251

Kurz HD, Salvadori N (2000a) Classical roots of input-output analysis: a short account of its long prehistory. Econ Syst Res 12:153-179

Kurz HD, Salvadori N (2000b) Economic dynamics in a simple model with exhaustible resources and a given real wage rate. Struct Change Econ Dyn 11:167-179

Kurz HD, Salvadori N (2001) Classical economics and the problem of exhaustible resources. Metroeconomica 52:282-296

Kurz HD, Salvadori N (2006) Input-output analysis from a wider perspective: a comparison of the early works of Leontief and Sraffa. Econ Syst Res 18:373-390

Kurz HD, Salvadori N (2009) Ricardo on exhaustible resources, and the hotelling rule. In: Aiko I, Kurz HD (eds) The history of economic theory: Festschrift in honour of Takashi Negishi. Routledge, London

Kurz HD, Salvadori N (2011) Exhaustible resources: rents, profits, royalties and prices. In: Caspari V (ed) The evolution of economic theory: essays in honour of Bertram Schefold. Routledge, London 
Kurz HD, Salvadori N (2015) The classical approach to exhaustible resources: Parrinello and the others. In: Kurz HD, Salvadori N (eds) Revisiting classical economics: studies in long-period analysis. Routledge, London

Lager C (2001) A note on non-stationary prices. Metroeconomica 52:297-300

Leontief W (1953) Dynamic analysis. In: Leontief W (ed) Studies in the structure of the American economy. Oxford University Press, London

Leontief W (1970) The dynamic inverse. In: Carter AP, Brody A (eds) Contributions to input-output analysis. Reprinted In: Input-output economics, W. Leontief. London: Oxford University Press

Lin X, Polenske KR (1995) Input-output anatomy of China's energy use changes in the 1980s. Econ Syst Res 7:67-84

Livesey DA (1973) The singularity problem in the dynamic input-output model. Int J Syst Sci 4:437-440

Luenberger DG, Arbel A (1977) Singular dynamic Leontief systems. Econometrica 45:991-995

McManus M (1957) Self-contradiction in Leontief's dynamic model. Bull Econ Res 9:1-21

Morishima M (1959) Some properties of a dynamic Leontief system with a spectrum of techniques. Econometrica 27:626-637

Mukhopadhyaya K, Chakraborty D (1999) India's energy consumption changes during 1973/74 to 1991/92. Econ Syst Res $11: 423-438$

Parrinello S (1983) Exhaustible natural resources and the classical method of long-period equilibrium. In: Kregel J (ed) Distribution, effective demand and international economic relations. Macmillan, London

Parrinello S (2001) The price of exhaustible resources. Metroeconomica 52:301-315

Parrinello S (2004) The notion of effectual supply and the theory of normal prices with exhaustible natural resources. Econ Syst Res 16:311-322

Petri F (2011) On some aspects of the debate on the gravitation of market prices to long-period prices. In: Ciccone R, Gehrke C, Mongiovi G (eds) Sraffa and modern economics. Routledge, London

Ravagnani F (2008) Classical theory and exhaustible natural resources: notes on the current debate. Rev Polit Econ 20:79-93

Ricardo D (1951-73) [1817] On the principles of political economy and taxation. In: The works and correspondence of David Ricardo, volume I, edited by Sraffa P, with the collaboration of Dobb M. H. Cambridge University Press, Cambridge

Salvadori N (1982) Existence of cost-minimizing systems within the Sraffa framework. Zeitschrift für Nationalökonomie 42:281-298

Salvadori N (1985) Switching in methods of production and joint production. Manch Sch 53:156-178

Sargan JD (1958) The instability of the Leontief dynamic model. Econometrica 26:381-392

Schefold B (1989) Mr Sraffa on joint production and other essays. Unwin Hyman, London

Schefold B (2001) Critique of the corn-guano model. Metroeconomica 52:316-328

Solow R (1952) On the structure of linear models. Econometrica 20:29-46

Solow R (1959) Competitive valuation in a dynamic input-output system. Econometrica 27:30-53

Solow R (1974) The economics of resources or the resources of economics. Am Econ Rev 64:1-14

Sraffa P (1960) Production of commodities by means of commodities. Prelude to a critique of economic theory. Cambridge University Press, Cambridge

Steenge AE (1990) On the complete instability of empirically implemented dynamic Leontief models. Econ Syst Res 2:3-16

Takayama A (1974) Mathematical economics, 2nd edn. Cambridge University Press, Cambridge

Treloar GJ (1997) Extracting embodied energy paths from input-output tables: towards an input-output-based hybrid energy analysis method. Econ Syst Res 9:375-391

Weber C, Schnabl H (1998) Environmentally important intersectional flows: insights from main contributions identification and minimal flow analysis. Econ Syst Res 10:337-356

Wilting HC, Biesiot W, Moll HC (1999) Analysing potentials for reducing the energy requirements of households in the Netherlands. Econ Syst Res 11:233-243 